\title{
ética na pesquisa com crianças: uma revisão da literatura brasileira das ciências
}

\section{humanas e sociais ${ }^{1}$}

\author{
renata lopes costa prado ${ }^{2}$ \\ universidade federal fluminense - brasil \\ maria cristina gonçalves vicentin ${ }^{3}$ \\ pontifícia universidade católica de são paulo - brasil \\ fulvia rosemberg 4 \\ (in memoriam)
}

resumo

O debate sobre a ética em pesquisa com seres humanos, no contexto nacional, tem se intensificado nas duas últimas décadas. Pesquisadores das ciências sociais e humanas, com alguns avanços e muitos obstáculos, convergem na recusa do modelo biomédico como referência para todo o fazer científico. $\mathrm{O}$ artigo busca dar visibilidade às questões que pesquisadores dessas áreas vêm discutindo quanto à ética na pesquisa com crianças. Para tanto, analisam-se artigos e capítulos de livros brasileiros que discutem o tema. São focalizados os vínculos entre política e ciência; a desigual relação de poder adulto-criança, a construção de procedimentos que permitam uma efetiva escuta das crianças e a participação destas nos processos de investigação. O posicionamento central dos textos, com o qual nos alinhamos, sustenta que normas éticas não bastam para assegurar às crianças o lugar de atores sociais, sendo necessária uma nova compreensão da posição da criança em pesquisas, assim como da posição do próprio pesquisador nesta relação. Argumenta-se também que as férteis discussões acerca das pesquisas com crianças podem contribuir com o debate mais geral sobre a regulação nacional da ética em pesquisa com seres humanos nas áreas das ciências humanas e sociais.

palavras-chave: ética; crianças; pesquisa; estudos sociais da infância.

\section{ethics in research with children: a review of the brazilian human and social sciences literature}

abstract

The debate on ethics around research involving human beings, in the national context, has intensified in the last two decades. Social sciences and Humanities researchers, with few advances and many hurdles, converge on the refusal of the biomedical model as a reference for all scientific work. The article seeks to give visibility to issues that researchers from these areas have been debating about the ethics in research involving children. For this purpose, Brazilian articles and book chapters that discuss on the subject

\footnotetext{
${ }^{1}$ Agradecimentos: Carmem Lúcia Sussel Mariano e Júlia Rosemberg

2 E-mail: renata.lopescp@gmail.com

${ }^{3}$ E-mail: cristinavicentin@gmail.com

${ }^{4}$ Fúlvia Rosemberg foi pesquisadora da Fundação Carlos Chagas e professora do Programa de Estudos Pós-graduados em Psicologia Social da PUC-SP. Falecida em 2014, ela era uma das pioneiras no debate brasileiro acerca da ética em pesquisas com crianças, tendo sido organizadora e mediadora da mesa-redonda que deu origem ao mais antigo artigo aqui analisado, Implicações éticas provenientes da utilização de crianças como sujeito de pesquisa (FCC, 1979). Rosemberg é co-autora de uma versão preliminar, não publicada, do presente texto. A elaboração da versão final foi acompanhada por sua filha, Júlia.
} 
were analyzed. The investigation was focused on links between politics and science, the unequal adult-child power relationship, the development of procedures that allow an effective listening to children and the children's participation in the research processes. The central position of the literature, with which we agree, defends that ethical standards are not enough to ensure children the role of social actors, requiring a new understanding of the role of children in research, as well as concerning the own researcher in this relationship. It is argued that the fruitful discussions on research with children can contribute to the more general debate on national ethics regulation in research involving human beings in the areas of humanities and social sciences.

keywords: ethics; children; research; childhood social studies.

\section{ética en la investigación con niños: una revisión de la literatura brasileña de las ciencias humanas y sociales}

resumen

El debate sobre la ética en la investigación con seres humanos en el contexto nacional ha venido intensificándose en las dos últimas décadas. Investigadores de las ciencias sociales y humanas, con algunos avances y muchos obstáculos, convergen en el rechazo del modelo biomédico como referencia para todo ejercicio científico. El artículo busca dar visibilidad a aquellas cuestiones que investigadores de estas áreas vienen discutiendo sobre la ética en la investigación con niños. Con esta finalidad, se analizan artículos y capítulos de libros brasileños que abordan el tema. Son focalizados los vínculos entre política y ciencia, la desigual relación de poder adulto-niño, la construcción de procedimientos que permitan una efectiva escucha de los niños y la participación de éstos en los procesos de investigación. El posicionamiento central de los textos, con el cual nos alineamos, sostiene que las normas éticas no son suficientes para asegurar a los niños el lugar de actores sociales, siendo necesaria una nueva comprensión de la posición del niño en la investigación, así como la del propio investigador en esta relación. Se argumenta también que las fértiles discusiones acerca de las investigaciones con niños pueden contribuir con el debate más general sobre la regulación nacional de la ética en la investigación con seres humanos en las áreas de las ciencias humanas y sociales.

palabras clave: ética; niños; investigación; estudios sociales de la infancia. 
ética na pesquisa com crianças: uma revisão da literatura brasileira das ciências

humanas e sociais

O debate sobre a ética em pesquisa tem se intensificado nas duas últimas décadas, impulsionado pela ampliação do controle social sobre as pesquisas, que tem como um de seus marcos a promulgação pelo Ministério da Saúde da Resolução 196, em 1996, e de sua substituta, a Resolução 466, de 2012, que regula a pesquisa com seres humanos ${ }^{5}$. As duas resoluções têm sido objeto de intensas críticas no âmbito das ciências humanas e sociais (CHS) por generalizarem pressupostos das ciências biomédicas para as demais áreas do conhecimento, isto é, partindo de experiências sobre o fazer pesquisa "nos" seres humanos, elas se propõem a prescrever procedimentos e normas também para as pesquisas "com" os seres humanos, mais características das CHS. Em meio a embates protagonizados pela Comissão Nacional de Ética em Pesquisa e pelo Fórum de Ciências Humanas, Sociais e Sociais Aplicadas, criado em julho de 2013, com associações científicas dessas áreas, uma resolução complementar à 466, específica para essas ciências, entrou em vigor em 2016. A Resolução 510/16 faz avançar o debate sobre o tema, mas mantém acesas controvérsias em torno da regulamentação da ética em pesquisa por esta continuar subordinada ao campo biomédico, dada a sua inserção institucional no Ministério da Saúde.

Entendendo que as pesquisas com crianças se oferecem para tal debate como um potente analisador, isto é, como situação crítica que permite arguir determinadas naturalizações e explicitar o jogo de forças aí atuante (LOURAU, 1996), nosso intuito neste artigo é dar visibilidade às questões que a comunidade científica vem discutindo quanto à ética na pesquisa com esse grupo etário. A infância é uma construção sócio-histórica que se funda na desigualdade estrutural

\footnotetext{
${ }^{5}$ Além dessas resoluções específicas, o marco legal sobre ética na pesquisa com crianças, no Brasil, baseia-se também no Estatuto da Criança e do Adolescente, de 1990. Cabe lembrar, ainda, de outro conjunto de normativas internacionais das quais o Brasil é signatário: a Convenção Internacional sobre os Direitos da Criança (1989) e demais instrumentos orientadores no campo da infância (como as Regras Mínimas das Nações Unidas para Administração da Justiça Juvenil -Regras de Beijing- e as Regras Mínimas das Nações Unidas para a Proteção dos Jovens Privados de Liberdade, do Sistema Global dos Direitos Humanos).
} 
de poder adulto-criança. Configurando as relações de idade como relações de poder é que o debate ético pode nos oferecer pistas dos modos pelos quais distintas concepções de pesquisa veiculam distintas concepções de infância e ensejam, por sua vez, atitudes ético-políticas igualmente distintas. Pretendemos, portanto, ao discutir parâmetros e dilemas éticos na pesquisa com crianças, evidenciar a dimensão política da ética. Tais objetivos se traduzem, neste artigo, pela apresentação de um levantamento de textos acadêmicos publicados no Brasil que refletem sobre a ética em pesquisa com crianças ${ }^{6}$ nas CHS. Este artigo descreve características do contexto de produção dos textos analisados e prossegue na apresentação e discussão das concepções de ética que os textos sustentam, os problemas que levantam e as recomendações que apontam. Estas podem ser um bom ponto de partida para a construção de uma pauta ético-política para pesquisadores $(\mathrm{as})^{7}$ no seu trabalho com crianças. Antes, porém, faremos uma brevíssima apresentação dos procedimentos adotados na constituição e análise do corpus.

\section{procedimentos para constituição do corpus e sua análise}

O corpus é constituído por 29 textos publicados no Brasil em periódicos acadêmicos ou livros até 2016. Para o levantamento bibliográfico consultou-se bases de dados como o Scielo, o Portal de Periódicos da Capes, a Redalyc e o Google Acadêmico, além dos catálogos eletrônicos dos acervos de diversas bibliotecas - da Universidade de São Paulo, da Universidade Federal de São Paulo, da Pontifícia Universidade Católica de São Paulo, da Universidade Estadual de Campinas, da Fundação Carlos Chagas, da Universidade Federal Fluminense, da Universidade Federal do Rio de Janeiro, da Universidade Federal da Bahia, da Universidade de Brasília, da Universidade Federal do Rio Grande do Sul e da Universidade Federal de Minas Gerais. Os descritores utilizados nessas buscas foram "criança, pesquisa e ética" e "infância, pesquisa e ética". Foram

\footnotetext{
${ }^{6}$ Criança entendida como pessoa até 18 anos, como na Convenção Internacional sobre os Direitos da Criança.

${ }^{7}$ Abandonamos, aqui, a fórmula o(a) e adotamos o genérico masculino, apesar da grande maioria de pesquisadoras mulheres entre aqueles(as) que tratam do tema.
} 
também consultadas as referências contidas nos próprios textos e em nossos acervos pessoais. Os textos assim localizados foram lidos e incluídos no corpus quando apresentavam uma discussão sobre ética na pesquisa no âmbito das CHS.

Com base nestes procedimentos, foram localizados 11 artigos e 18 capítulos de livro que tratam do tema (referências no Apêndice 1$)^{8}$. Os textos foram analisados usando-se procedimentos de análise de conteúdo (BARDIN, 2002) e adotando-se as seguintes categorias de análise: ano de publicação, área de conhecimento dos autores, nacionalidade dos autores, sexo dos autores, referenciais e subsídios, legislação citada, concepção de ética, questões levantadas e recomendações referentes à ética na pesquisa com crianças.

\section{caracterização da produção sobre ética na pesquisa com crianças}

A produção acadêmica localizada no Brasil que se refere à ética nas pesquisas com criança em CHS é muito recente: $83 \%$ dos textos tem sua data de publicação entre os anos de 2007 e 2016. Apenas um texto foi publicado antes dos anos 2000, o artigo, já citado, Implicações éticas provenientes de utilização de crianças como sujeitos de pesquisa: mesa-redonda, que documenta a mesa-redonda realizada pela Fundação Carlos Chagas, ao final da década de 1970, e que reuniu pesquisadores de diferentes áreas do conhecimento (FCC, 1979) 9

Se para situar este aumento da preocupação com a questão não se pode olvidar da instalação de comitês de ética em instituições de pesquisa, é necessário lembrar também da mudança paradigmática dos conceitos de criança e infância que tem orientado a produção de conhecimento e o reconhecimento de novos direitos para esse segmento etário. A expressão maior desse movimento no contexto acadêmico é a emergência dos estudos sociais da infância, um campo interdisciplinar que se organiza a partir de pressupostos comuns, entre os quais destacam-se a concepção de criança como ator social; a ideia de que a infância é

\footnotetext{
8 Por não dispormos, no Brasil, de bases de dados informatizadas que cataloguem capítulos de livros, diferentemente do que ocorre com periódicos acadêmicos, este levantamento não pode ser considerado exaustivo.

9 Foram eles: Manoela Carneiro da Cunha; Maria de Fátima Pacheco Jordão; Maria Nilde Mascellani, Rosa Maria S. Macedo; Marisa Lobo; Rosa Maria Fischer; Ruth Cardoso e Sergio Luna; com a mediação de Fúlvia Rosemberg.
} 
socialmente construída; e a consideração da infância como categoria estrutural subordinada da sociedade, o que significa dizer que as sociedades ocidentais contemporâneas estruturam-se em torno de eixos de dominação, sendo a idade um desses eixos, ao lado de outros, como classe, raça e gênero. A emergência dos estudos sociais da infância em contexto internacional tem sido localizada na década de 1980. Apesar de alguns textos precursores, apenas no início dos anos 2000 o campo começa a consolidar-se em contexto nacional.

A quase totalidade dos textos localizados é de autoria de brasileiros (83\%). Cinco textos são de autoras estrangeiras (ALDERSON, 2005; FERREIRA, 2008; 2010; TOMÁS, 2008; FERNANDES, 2016) e um foi escrito em co-autoria com uma brasileira (FRANCISCHINI; FERNANDES, 2016). Três aspectos convêm serem observados em relação a este grupo de textos. Em primeiro lugar, o fato dos autores serem quase todos portugueses, com exceção da inglesa Priscilla Alderson. Portugal é um país que tem contribuído muito para com a produção dos estudos sociais da infância em língua portuguesa, tendo ampla penetração no Brasil, o que está diretamente relacionado ao segundo aspecto a ser observado: todos esses textos referenciam-se teoricamente nos estudos sociais da infância, o que mais uma vez evidencia a importância desse campo para as discussões sobre pesquisas com crianças.

O terceiro aspecto a ser observado refere-se a esse grupo de textos, mas não apenas a ele: todos os textos de autoria de pesquisadores estrangeiros foram escritos por mulheres e, entre as 29 produções do corpus, apenas três contam com pesquisadores homens enquanto co-autores. Este é um dado que corrobora a afirmação de Prado e Freitas (no prelo) sobre o perfil de quem envolve crianças em suas pesquisas: quase sempre são mulheres. Os autores chamam a atenção para a importância de se "fortalecer linhas de pesquisa direcionadas a apreender as maneiras pelas quais o fato das crianças se constituírem como uma 'temática feminina' impacta o nosso conhecimento sobre infância e, mais indiretamente, a própria vida das crianças" (PRADO; FREITAS, no prelo, p. 1), pois apesar de haver certa tradição nos estudos feministas de reflexão crítica sobre a conexão 
supostamente natural entre mulheres e crianças, tais estudos focalizam as implicações para a vida das mulheres, e não das crianças.

Em relação às áreas de conhecimento dos autores, considerando aquelas em que eles se graduaram, mas que nem sempre representa a sua atual área, a psicologia é a mais frequentemente encontrada (45\% dos textos foram escritos exclusivamente por psicólogos), seguida pela educação ( $24 \%$ são de autoria de pedagogos). Outros quatro textos (14\%) são de co-autoria entre pesquisadores de áreas distintas e há ainda textos escritos por autores da filosofia (1), da sociologia (2), do direito (1) e de letras (1).

O fato, porém, de as ciências sociais praticamente não abrigarem autores que publicaram reflexões sobre ética na pesquisa com crianças, não significa que elas não adentraram os textos. Ao contrário, dentre os 29 textos localizados, podemos afirmar que 23 deles (79\%) fazem referência aos estudos sociais da infância, um campo cujas principais contribuições provêm da sociologia da infância e da antropologia da criança.

Esta intensa referência aos estudos sociais da infância, associada à sua entrada recente em cenário brasileiro, parece sugerir que a emergência desta preocupação ética no Brasil estaria associada ao aparecimento deste novo sujeito nas ciências sociais: a criança. Com efeito, como revisões de literatura têm mostrado (SOARES, 2006), a reflexão sobre ética na pesquisa com crianças é um importante tema dos estudos sociais da infância em países como Inglaterra, França, Estados Unidos e Portugal. Neste sentido, é provável que a literatura internacional venha instigando pesquisadores brasileiros que começaram, nos últimos anos, a trabalhar com os aportes desse campo no país.

Identificamos uma variedade de enfoques teóricos e metodológicos nos textos aqui analisados: pesquisa participante/pesquisa-intervenção, etnografia, estudos feministas, estudos sobre o desenvolvimento humano, para mencionar alguns. Além disso, encontramos aportes de Mikhail Bakhtin, Walter Benjamin, Lev Vigotski, Erving Goffman e de outros autores filiados a correntes sóciohistóricas. Tal diversidade de enquadres convive com uma forte afinidade com os 
temas do poder e da busca de dialogia nas relações entre adultos e crianças, temas que abrem instigantes questões na discussão sobre cuidados éticos na pesquisa com crianças.

Destacamos uma ausência marcante: a indiferenciação quanto às "idades da infância". Isto é, a totalidade dos textos analisados omite especificidades dos bebês nas reflexões sobre pesquisas envolvendo crianças e suas implicações éticas.

Causou-nos certa estranheza (discutível, com certeza) que nem todos os textos do corpus mencionem a legislação: pouco mais do que a metade (16) dos 29 textos mencionam alguma legislação. Quando o fazem, citam, particularmente, a Convenção Internacional sobre os Direitos da Criança (treze textos), o ECA (sete textos) e as Resoluções 196 e 466 (seis textos).

Assim, críticas à legislação e aos protocolos referentes à ética em pesquisa puderam ser identificadas, principalmente entre os textos mais recentes (BARBOSA, 2014; PEREIRA, 2015; FERNANDES, 2016; FREITAS; PRADO, 2016; entre outros). Freitas e Prado (2016) criticam a primazia dada pela legislação a grupos considerados "com autonomia plena" (nomeadamente, os adultos) para a participação em pesquisas. Os autores aventam, ainda, a hipótese de que o atual marco legal sobre ética na pesquisa envolvendo seres humanos acaba por privilegiar estudos que assumem a perspectiva da criança como objeto (e não como sujeito ou ator social), pois valoriza o previsível e abre pouco espaço para o reconhecimento da autonomia do outro.

A afirmação de Pereira (2015, p. 298-299) serve como boa síntese das preocupações a esse respeito expressas nos textos:

\footnotetext{
Por um lado, testemunhamos no meio acadêmico a intensificação de discursos que afirmam ser imprescindível a participação das crianças na produção de conhecimento sobre elas, mas por outro, vemos que a institucionalização - e mesmo a judicialização - dos debates sobre ética na pesquisa não têm caminhado no mesmo compasso, na medida em que não tem reconhecido as crianças como sujeitos com capacidade de enunciação.
} 


\section{concepções de ética}

A descrição que se segue baseou-se, exclusivamente, nas concepções de ética explicitadas nos textos, não se entrando, portanto, em eventuais concepções implícitas. Além disto, ela se refere à concepção que identificamos como sendo a predominante, posto que um mesmo texto pode sustentar concepções híbridas. Assim procedendo, identificamos que 22 (76\%) dos 29 textos explicitam pelo menos uma concepção de ética (ou de moral). Como, neste artigo, não pretendemos problematizar as concepções de ética que atravessam as práticas de pesquisa, mas identificar seus usos e inflexões pelos pesquisadores, nos valemos, para dar conta da tarefa de conceituação, das categorias já propostas por La Taille, Souza e Vizioli (2004) no artigo Ética e educação: uma revisão da literatura educacional de 1990 a 2003.

Os autores buscam evidenciar distinções entre ética e moral apreendidas na literatura educacional. Para tanto, apresentam inicialmente algumas definições que distinguem ética e moral. A moral diz respeito a normas de conduta ou a normatização. Isto é, valores, princípios e regras legitimados por uma comunidade ou indivíduo (LA TAILLE; SOUZA; VIZIOLI, 2004, p.98). Já a ética se refere a uma reflexão - filosófica ou científica - sobre os valores, princípios e regras. Outra diferença entre moral e ética é que elas focalizariam duas problemáticas diferentes, ainda que indissociáveis: "a moral referir-se-ia à dimensão do dever, enquanto a ética diria respeito à dimensão da felicidade e às formas de alcançá-la. ComteSponville (1998) diz que a moral corresponde à pergunta 'como devo agir?', e a ética a outra questão: 'que vida quero viver?'” (LA TAILLE; SOUZA; VIZIOLI, 2004, p. 98). Os autores seguem trabalhando a distinção moral e ética, inspirados principalmente em Paul Ricoeur, reservando à ética a procura de uma vida boa com os outros e para os outros, em instituições justas. Já a moral seria a articulação entre esta perspectiva e as normas (que seriam universais e que se efetuam por coação). Em relação ao nosso corpus, mantivemos a análise do eixo moral/ética, na 
diferença normas/reflexão sobre normas, tal como proposto pelos autores ${ }^{10}$. No entanto, sentimos necessidade de tornar um pouco mais precisa a inflexão dever/felicidade ou "vida boa", especialmente pela singularidade da construção sócio-histórica da infância. De fato, a sociedade ocidental moderna, ao produzir a consciência da particularidade da infância - isso que Ariès (1981) chamou de "o sentimento de infância" - situou a criança no centro de intenso interesse psicológico e preocupações morais, na perspectiva de "conformá-la às normas". No século $X X$, no entanto, uma nova sensibilidade e uma nova atitude em relação às crianças começou a se construir, visível na produção e circulação de discursos e práticas em defesa de seus direitos. Ora, os fundamentos políticos e jurídicos que influenciaram essa mutação poderiam ser rapidamente relacionados à ética, na perspectiva da felicidade/vida boa. Mas, estudiosos da infância têm problematizado esta mutação, entendendo que tais direitos ainda se voltam mais para os direitos de proteção do que para a legitimação da perspectiva da criança em suas singulares relações com os adultos (CASTRO, 2008; ROSEMBERG; MARIANO, 2010). Além disto, sustentam pretensões universalistas, desconsiderando as especificidades sociais, históricas e culturais (e etárias!) em que as crianças, em diferentes contextos, crescem, vivem e se desenvolvem e, em termos políticos, podem fomentar uma condição de incapacidade sócio-política da criança e dos jovens (CASTRO, 2008). É o caso de conceitos como vulnerabilidade, proteção e desenvolvimento, acionados na relação de adultos com crianças e adolescentes (ROSEMBERG; MARIANO, 2010), sempre que inscrevam a infância em sua menoridade política. Assim, a vida boa, no caso da infância, a nosso ver, é relativa às perspectivas que problematizam o lugar social de crianças e as discriminações etárias a que estão expostas.

10 Cabe salientar que tal distinção encontra suas bases nas críticas de Nietzsche aos valores universais ou a uma ética de fundamentação, e à sua proposição de uma ética de reflexão da própria moral ante outras morais, que renuncia ao julgamento para liberar o indivíduo à alteridade e para refletir sobre a sua própria moral. O problema desloca-se, assim, da definição do que é o justo para a relação e a prática de avaliação, ou seja, justamente a questão do valor dos valores e da interpretação. Trata-se de uma capacidade de deixar normas e valores concretos se formarem de acordo com as condições de existência e serem por elas perspectivados para permitir a emergência efetiva da justiça (MELO, 2005). 
Feito este esclarecimento, passemos à análise do corpus. A maioria dos textos (19) explicita antes uma concepção de ética do que de moral. Apenas três apresentam a ética como respeito às normas e prescrições legais. Dentre os dezenove, doze contemplam uma reflexão sobre valores, princípios e regras. Nessa concepção, os autores enfatizam a responsabilidade (individual e coletiva) do pesquisador e da comunidade científica quanto às escolhas metodológicas e aos efeitos da produção de conhecimento. Destacam tanto a necessidade de analisar as relações estruturais de poder adulto-criança, quanto a assunção de compromissos com os direitos de participação (como o de "levar a sério" os sentidos construídos pelas crianças), de controle do processo de pesquisa pelas crianças, e com implicações para as suas vidas concretas.

Tal como La Taille e colaboradores (2004), encontramos um número reduzido de textos (sete entre os 22) que fazem, mais explicitamente, referência à concepção de ética como "vida boa". Esse conjunto de textos enfatiza a concepção de criança como sujeito de conhecimento e como ator social e o papel da pesquisa nessa construção. É o caso de Souza e Salgado (2008), quando formulam a perspectiva ética a partir de Bakhtin, como o padrão dos atos reais que cada um executa na vida que depende de uma construção permanente dos sujeitos históricos. Formula-se, assim, o compromisso e a responsabilidade do pesquisador (e de qualquer um) com a criação permanente da condição humana, quando a pesquisa faz-se ato educativo, conjugando conhecimento e intervenção, e instaurando transformações nas formas de olhar e definir a própria experiência, a do pesquisador e a do outro, mais especificamente a criança.

É o caso também de Ferreira (2008, p. 149), quando sustenta que o sentido da pesquisa é indissociável dos modos pelos quais se concebem as crianças, sendo fundamental assegurar o "estatuto da autonomia", "equidade conceitual" e "simetria ética com os adultos". Ou seja, para ela, "tal como qualquer outra pessoa, as crianças têm direitos [...] e devem ser [...] informadas, ouvidas, e, crescentemente implicadas na pesquisa" (FERREIRA, 2008, p. 155). É o caso, ainda, das preocupações de Castro (2008) quando se interroga se as pesquisas assumem, 
em sua concepção, responsabilidade para com o bem-estar de crianças e jovens. Na mesma direção, Alderson (2005) atrela a pesquisa ao estrito respeito aos direitos da criança, o que implica em uma atitude de promoção de justiça social e de garantia efetiva dos direitos de participação.

É necessário, ainda, mencionar que as distinções entre essas duas concepções de ética apreendidas nos textos aqui analisados - aquela que privilegia as "reflexões sobre normas e valores" e a que focaliza a construção de uma "vida boa"- não são rígidas. A nosso ver, esta permeabilidade das fronteiras entre os dois grupos de textos pode ser explicada por duas razões principais: a primeira se refere à proximidade entre as concepções de infância e de sociedade/cultura observada nos textos embasados nos estudos sociais da infância e aqueles inspirados em Bakhtin, Benjamim, Vigotski ou nos estudos feministas.

A outra razão a explicar tal permeabilidade entre os grupos de textos decorre da direção ético-política dos movimentos de defesa dos direitos da criança de construção de relações democráticas entre adultos e crianças. Nessa perspectiva, os direitos, pensados como construção histórica e sempre inacabada, não se reduzem às normas e deveres prescritos, mas engajam a permanente produção de "sujeitos" e de "direitos".

\section{questões e dilemas éticos}

No corpus aqui analisado, desde a mesa redonda organizada pela Fundação Carlos Chagas em 1979 até os dias atuais, pesquisadores vêm se perguntando se haveriam, e quais seriam, especificidades da pesquisa com crianças. A imensa maioria dos textos $(76 \%)$ sugere que as relações de poder entre adultos e crianças (DELGADO; MÜLLER, 2005a; CAMPOS, 2008; CASTRO, 2008; FERREIRA, 2008; FRANCISCHINI; FERNANDES, 2016, entre outros) constituem aspecto diferenciador entre essas pesquisas e aquelas desenvolvidas com outros grupos etários. Consideramos que esta questão dialoga com a discussão proposta por Bourdieu (1999): se a dissimetria entre as posições de pesquisador e "pesquisado" 
está sempre posta na pesquisa, ela pode ser redobrada quando ocorre também uma diferenciação hierárquica entre as posições sociais ocupadas por eles.

Neste aspecto, as pesquisas com crianças evocariam questões equivalentes às que já foram levantadas com respeito a outros segmentos sociais tratados como "minorias": mulheres, negros, indígenas, pessoas oriundas de países periféricos, entre outros. Daí, talvez, a razão da presença, por exemplo, dos estudos feministas como subsídio para a reflexão de alguns autores sobre as pesquisas com crianças (CASTRO, 2008; DELGADO; MÜLLER, 2005b; BARBOSA, 2014). Mas, ao lado de possíveis aproximações entre as pesquisas com esses outros grupos, destacamos, também, diferenças entre eles, porque as relações de poder manifestam-se diferentemente. Por exemplo, ao contrário do que acontece com os demais grupos subordinados, as crianças não costumam ser elas mesmas pesquisadoras ${ }^{11}$.

Nos textos analisados, as reflexões sobre as relações de poder entre adultos e crianças suscitaram várias questões referentes à ética na pesquisa: como romper com a lógica adultocêntrica (DELGADO; MÜLLER, 2005a)? Como lidar com a produção do adultocentrismo pelas próprias crianças (FERREIRA, 2008)? Como lidar com o risco de as crianças dizerem o que acreditam que o adulto quer ouvir (CAMPOS, 2008; TOMÁS, 2008)? Como superar nossa dificuldade de escutálas (CRUZ, 2010)?

Os textos problematizam como o pesquisador adulto pode lidar com as especificidades das crianças (e das relações intergeracionais) de forma a respeitálas como atores sociais e a protegê-las de situações potencialmente danosas. Alguns autores, além disso, discutem também as competências das crianças, levantando perguntas como: qual é a competência da criança para decidir sobre sua participação na pesquisa (FCC, 1979; FERREIRA, 2010)? Até que ponto seu acordo para participar foi sustentado por informação consistente ou suficiente? Até que ponto sua participação foi ou é voluntária? Ou ao contrário, sua participação é ou foi induzida pelo pesquisador (FERREIRA, 2010)?

\footnotetext{
${ }^{11} \mathrm{O}$ texto de Alderson (2005) traz exemplos de algumas possíveis exceções para grupos específicos de crianças.
} 
Os possíveis riscos para as crianças produzidos pela pesquisa foram abordados, tanto em termos de riscos físicos (FCC, 1979) em se tratando de pesquisas da área da saúde, quanto em relação a assuntos que possam provocar reações de estresse e sofrimento (CAMPOS, 2008; SÓLON; COSTA; ROSSETTIFERREIRA, 2008; entre outros).

Um grupo de questões relacionadas, simultaneamente, ao respeito às crianças como atores sociais e à sua proteção aborda a publicização da pesquisa. Kramer (2002), por exemplo, pergunta: os nomes das crianças devem ser divulgados? Conforme a autora, se, por um lado, divulgá-los pode acarretar sua exposição pública, por outro, usar números ou iniciais parece desconsiderar sua identidade e negar sua condição de sujeito, o que pode ser incoerente com o referencial teórico e a perspectiva política da pesquisa. A autora relata experiências de seu grupo de pesquisa que optou seja por nomear a criança e ocultar a instituição de origem, ou por garantir, para as crianças, a possibilidade de escolher os nomes pelos quais seriam designadas.

Kramer (2001), Alvarenga, colaboradores (2012), Spinelli e Quinteiro (2015) discutem, ainda, como devolver os achados das pesquisas, evitando que crianças ou jovens sejam expostos e sofram com suas repercussões. Em outras palavras, é o que também Castro (2008) e Pereira (2015) se perguntam: os resultados das pesquisas são relevantes para as crianças como o são para os adultos pesquisadores? As pesquisas assumem responsabilidade para com o bem-estar de crianças e jovens no geral, para além daqueles que participaram da pesquisa?

Vale destacar, também, a preocupação de Correa (2008) sobre a responsabilidade de, ao término do estudo, o pesquisador oferecer, ao grupo de controle, as mesmas atividades realizadas com o grupo experimental ${ }^{12}$.

Por fim, encontramos em Alderson (2005) outro rol de questões, agora relacionadas à participação de crianças como pesquisadoras. A autora se pergunta como jovens pesquisadores podem trabalhar com adultos em termos razoavelmente

\footnotetext{
${ }^{12}$ Convém observar que nenhum texto analisado discutiu a adequação ética do desenho de grupo experimental e de controle em investigações com crianças.
} 
iguais, informados e livres de pressão. Quanta responsabilidade é justo esperar que as crianças assumam e até que ponto os adultos deveriam intervir para apoiá-las ou controlar a pesquisa? Quanto tempo crianças e jovens deveriam dedicar à pesquisa além dos trabalhos ou estudos que realizam? Deveriam ser pagas? Em dinheiro ou em espécie? E quem deveria ter o controle sobre os dados e relatórios: crianças, adultos ou todos em conjunto?

Para algumas das questões apontadas, os textos analisados não oferecem respostas, tampouco se propõem a isto. São aspectos a serem considerados, sabendo-se que o melhor encaminhamento do pesquisador pode variar a cada pesquisa ou mesmo em seus diversos momentos ou etapas. Para outras questões, os autores partem de suas experiências em investigações com crianças, ou de suas reflexões sobre elas, para propor recomendações gerais, sistematizadas no próximo tópico. Tais recomendações não fecham questão, mantendo o debate em aberto, já que, como nos lembra Fonseca (2011, p. 50), dilemas éticos “são, por definição, sem solução e a discussão deles serve antes de tudo para ajudar a enfrentá-los honestamente".

\section{recomendações éticas}

Foram muitas e diversificadas as recomendações apreendidas nos textos sobre cuidados éticos nas pesquisas com crianças. Identificamos nove grandes grupos a que tais recomendações se relacionam: a ética como busca permanente; os requisitos do pesquisador; as premissas para a pesquisa; os cuidados com os riscos de sofrimento adicionais; o consentimento ou assentimento informado; os comitês de ética; os métodos e procedimentos; a escuta e a análise; e a redação e divulgação do texto.

O primeiro grupo de recomendações nos lembra de que as melhores normas formais ou legais são insuficientes para a condução ética das investigações com crianças. O termo "reflexividade reflexa", utilizado por Bourdieu (1999), talvez possa nomear, adequadamente, as recomendações aqui agrupadas. Delgado, Müller (2008) e Sant'Ana (2010) sustentam que a preocupação com a 
ética deve-se constituir como um processo contínuo. Ferreira (2010) empresta de Skånfors (2009) a designação "radar ético", para falar de um alerta sensível, necessário ao pesquisador, para detectar os modos pelos quais as crianças podem expressar resistência e recusa. Já Tomás (2008) recomenda que o pesquisador não abra mão de uma "vigilância epistemológica contínua". Assim, mais do que normas pré-estabelecidas, o que faz a condução ética de uma pesquisa é a busca permanente do pesquisador em respeitar as crianças junto às quais sua pesquisa é desenvolvida.

O segundo grupo de recomendações aponta para os requisitos de formação e supervisão do pesquisador, tema particularmente discutido por Lisboa, Habigzang e Koller (2008). Para elas, os pesquisadores precisam ter "excelente base teórica" para evitar falsas interpretações de dados, erros de análise e generalizações inadequadas; eles também precisam estar capacitados para intervir e dar o suporte necessário às crianças. Recomendam, ainda, que haja uma supervisão, que o trabalho seja realizado em equipe de forma a possibilitar o compartilhamento das análises e a discussão de encaminhamentos. Outro aspecto apontado pelas autoras, e também por Campos (2008), é a importância de se conhecerem as condições de vida das crianças e a cultura da população estudada, o que pode levar o pesquisador a compreender possíveis repercussões na comunidade da participação das crianças e evitar constrangimentos adicionais.

O terceiro grupo de recomendações trata de premissas para o trabalho com crianças. Diversos autores enfatizam a clareza teórica que o pesquisador precisa ter de que a criança é sujeito da cultura, da história e do conhecimento (KRAMER, 2002; ALDERSON, 2005; FREITAS; PRADO, 2016, entre outros) e, além disso, que ela deve ser vista como sujeito de direito (FCC, 1979). Lembram que crianças constroem sentidos para suas experiências, o que inclui a própria experiência na pesquisa (CASTRO, 2008). Outra premissa, daí derivada, refere-se à consideração quanto à heterogeneidade (e contradições) entre crianças e suas relações (KRAMER, 2002; DELGADO; MÜLLER, 2005b). Assim, a escuta das crianças e as análises dos dados não devem ter pretensão totalizadora (CARVALHO; MÜLLER, 
2010; FERREIRA, 2010), o que contribuiria para a disseminação de preconceitos e estereotipias (SOUZA; SALGADO, 2008; TOMÁS, 2008). Neste grupo de recomendações entram, ainda, a atenção à desigual relação de poder entre adultos e crianças, ponto destacado em quase todos os textos, como dito anteriormente. A recomendação geral é que o pesquisador lembre-se de que a sociedade ocidental moderna é adultocêntrica e que as relações entre adultos e crianças, bem como o conhecimento acadêmico, carregam esta marca. Daí a necessidade de se buscar romper com a naturalização de noções como vulnerabilidade, incompletude, dependência e incompetência quando associadas às crianças (FREITAS; PRADO, 2016; FERNANDES, 2016), pois como afirma Pereira (2015, p. 292), “o direito [das crianças] à voz, o direito de enunciar-se ou o direito de disputar a autoria dos discursos produzidos sobre si parecem ser ainda impotentes diante da hegemônica ideologia da proteção". A autora sublinha, assim, a necessidade de nos indagarmos acerca de discursos e realidades que produzimos ou referendamos com nossas pesquisas.

Parece ser prudente, portanto, desconfiar mais do ponto de vista adulto (CARVALHO; MÜLLER, 2010; SOUZA; SALGADO, 2008). É nesse sentido que autoras como Delgado e Müller (2005b) defendem que os traços que julgam ser distintivos das culturas da infância - ludicidade, fantasia do real, interatividade, por exemplo - sejam considerados na própria estruturação da pesquisa. Conforme afirmam, é necessário compreender a sensibilidade e a imaginação como formas legítimas de conhecimento. Outras autoras chamam atenção também para a legitimidade das formas de comunicar das crianças, pois se o pesquisador não estiver atento a isto poderá não ser capaz de escutá-las (LISBOA; HABIGZANG; KOLLER, 2008; FERREIRA, 2008; FERNANDES, 2016).

O quarto grupo de recomendações refere-se à necessária ponderação dos pesquisadores em relação a possíveis malefícios para as crianças ao participarem das pesquisas, inclusive em termos de tempo, medo, coerção e ansiedade (DELGADO; MÜLLER, 2008). Entram aqui, também, os cuidados para não se 
levantarem muitas expectativas sobre os resultados da pesquisa (CAMPOS, 2008) e para não se exporem as crianças (FCC, 1979; FERREIRA, 2010, entre outros).

Kramer (2002) destaca a importância de se negociar com as crianças participantes da pesquisa o que poderá ser divulgado. Ferreira (2010) complexifica o debate, ao afirmar que a "confidenciabilidade absoluta" também pode trazer problemas, caso surjam questões nas quais algum encaminhamento, em nome da proteção da criança, se faça necessário.

Outros riscos considerados são os advindos de perguntas que possam trazer à tona conteúdos emocionais ameaçadores (LISBOA; HABIGZANG; KOLLER, 2008; CAMPOS, 2008; ALVARENGA et al., 2012). Assim, os autores recomendam refletir sobre a pertinência das perguntas propostas para as crianças e buscar sua melhor formulação, cuidado que deve ser redobrado em pesquisas sobre temas potencialmente "mais delicados".

Três textos enfatizam a necessidade de o pesquisador acompanhar, se for preciso, o encaminhamento das crianças para atendimento psicológico ou outros serviços: Lisboa, Habigzang e Koller (2008); Sólon, Costa e Rossetti-Ferreira (2008); e Alvarenga e colaboradores (2012).

O quinto grupo de recomendações aponta para a necessidade do consentimento (ou assentimento) informado, um aspecto tratado em grande parte dos textos (ALDERSON, 2005; DELGADO; MÜLLER, 2005a, 2005b; CRUZ, 2010; SANT'ANA, 2010, entre outros). Os autores defendem que as crianças, seus pais ou responsáveis e as instituições envolvidas nas pesquisas sejam informados quanto à pesquisa e consultados sobre se querem ou não participar.

Ferreira (2010), no entanto, problematiza o caráter "informado" do consentimento, principalmente em relação às crianças pequenas. Ela aponta as dificuldades de explicar "completamente", e logo no início, o que é a pesquisa e quais são suas implicações. Relata que tem optado por informar as crianças de modo parcial, comunicando apenas o que considera ser relevante para que as crianças tomem uma posição. A autora considera, também, que o pesquisador 
deve estar atento para as muitas maneiras pelas quais as crianças podem expressar não querer participar.

Com a mesma preocupação, Fernandes (2016) cita a possibilidade de ensaiar com as crianças dinâmicas sobre como recusar participar do processo de pesquisa, o que pode ser especialmente útil no contexto das pesquisas desenvolvidas em instituições em que as crianças são atendidas e podem ter a impressão de que rejeitar a participação reduziria a atenção de profissionais para o seu tratamento ou sua demanda, como nos casos relatados por Alvarenga e colaboradores (2012).

Apesar de ser visto como recomendável entre os textos que compõem o corpus, vez ou outra, a necessidade do consentimento/assentimento é relativizada pelos autores, especialmente quando se aborda estudos de caso de atendimento clínico que inicialmente não se previa que passassem a compor os dados de uma pesquisa (ALVARENGA et al., 2012) ou quando se aborda a etnografia (BARBOSA, 2014). É provável que críticas à obrigação do consentimento informado fossem mais intensas entre os textos se, por um acaso, houvesse mais antropólogos entre seus autores. Como lembra Fonseca (2011, p. 41), em texto que não compõe o nosso corpus, esse dispositivo, popular sobretudo nas ciências médicas, enfrentou rejeição quase global na antropologia. Conforme a autora, ele é visto como "um artifício legal que protege mais o pesquisador do que o pesquisado", além disso, se o objetivo do trabalho de campo é justamente apreender lógicas culturais implícitas e nem sempre conscientes, não é possível pretender que os participantes prevejam todas as implicações de seu consentimento.

O sexto grupo de recomendações aborda as orientações dos autores em relação aos comitês de ética. Por um lado, alguns autores lembram a necessidade de submissão dos projetos de pesquisa a um comitê (DIAS; LEME; KOLLER, 2009; ALVARENGA et al., 2012; etc.). Por outro lado, defendem que as equipes de avaliação estejam bem capacitadas para poderem, inclusive, flexibilizar critérios de acordo com "casos específicos (por exemplo, violência doméstica), nos quais o 
melhor interesse da criança deve sobrepor-se à necessidade de obtenção de consentimento formal e escrito [...]" dos pais (LISBOA; HABIZANG; KOLLER, 2008, p. 176).

O sétimo grupo de recomendações trata dos métodos e procedimentos. $\mathrm{O}$ ponto central das recomendações aqui agrupadas talvez seja a busca por formas de pesquisar que permitam a efetiva escuta das crianças (CASTRO, 2008; FERREIRA, 2008; CARVALHO; MÜLLER, 2010, entre outros). Para grande parte dos autores, uma boa resposta a este desafio consiste na combinação de métodos e estratégias de pesquisa (CARVALHO; MÜLLER, 2010; CRUZ, 2010; KOSMINSKY, 2010). Sólon, Costa e Rossetti-Ferreira (2008), por exemplo, enfatizam a importância de os pesquisadores não limitarem as conversas com as crianças apenas a um tipo de narrativa, pois estratégias variadas podem favorecer diferentes expressões. Assim, é possível recorrer às entrevistas, ao uso de máquinas fotográficas para as crianças tirarem fotos de situações de seu cotidiano (CARVALHO; MÜLLER, 2010), às atividades com grupos de crianças (LEITE, 2008; CRUZ, 2010), entre outras estratégias. Conforme Delgado e Müller (2005b), para possibilitar a escuta das crianças é preciso apelar para a criatividade na definição dos instrumentos metodológicos. É necessário também ser flexível em relação aos procedimentos planejados de forma a respeitar o tempo e o interesse das crianças envolvidas (SÓLON; COSTA; ROSSETTI-FERREIRA, 2008).

As recomendações sobre privilegiar metodologias participativas por permitirem relações mais horizontais entre os atores e maior riqueza nas informações são recorrentes nos textos (TOMÁS, 2008; ALDERSON, 2005; DELGADO; MÜLLER, 2005a，2005b，2008; FERREIRA，2008; CARVALHO; MÜLLER, 2010; CRUZ, 2010; SPINELLI; QUINTEIRO, 2015; FRANCISCHINI; FERNANDES, 2016). Para Ferreira (2010), as crianças devem ser envolvidas, informadas, ouvidas e cada vez mais implicadas como pesquisadoras.

Alderson (2005), no entanto, adverte que nem mesmo o mais participativo dos métodos, ou seja, o trabalho com crianças pesquisadoras, garante o estabelecimento de relações de poder menos desiguais; pelo contrário, se os 
métodos não forem bem planejados e desenvolvidos, é possível que a pesquisa produza provas que reforcem a ideia de incompetência da criança.

A convivência prolongada do pesquisador no campo, como lembram Cruz (2010), Spinelli e Quinteiro (2015), aumenta a chance do estabelecimento de vínculos de confiança, possibilitando, por exemplo, que as crianças compartilhem com o pesquisador as suas discordâncias e permite também interpretações mais acuradas.

Outros aspectos abordados pelos autores que se relacionam a este grupo de recomendações foram: o planejamento cuidadoso do tempo (CARVALHO; MÜLLER, 2010; KOSMINSKY, 2010), já que o tempo do adulto pode ser diferente do tempo da criança; a atenção ao posicionamento físico de forma a estabelecer contato na mesma altura dos olhos das crianças (LEITE, 2008; CARVALHO; MÜLLER, 2010); a adequação da linguagem (LEITE, 2008; CARVALHO; MÜLLER, 2010; ALVARENGA et al., 2012); a consideração das experiências prévias das crianças como ponto de partida para o seu envolvimento na pesquisa (ALDERSON, 2005; CAMPOS, 2008; CARVALHO; MÜLLER, 2010); e a escolha cuidadosa do local da pesquisa (CARVALHO; MÜLLER, 2010; CRUZ, 2010; KOSMINSKY, 2010; PEREIRA, 2015).

O oitavo grupo de recomendações refere-se à escuta das crianças e à inclusão de suas falas na análise dos dados. Souza, Salgado (2008), Carvalho, Müller (2010), Cruz (2010) e Ferreira (2010) trazem interessantes reflexões sobre o desafio dos pesquisadores adultos ao escutarem crianças. Cruz (2010, p. 17), por exemplo, lembra que "ouvir é um processo interpretativo e que a diferença geracional implica perspectivas diversas, exigindo um real empenho do pesquisador para tentar apreender o ponto de vista da criança". Ela recomenda falta de pressa aos pesquisadores para que possam incorporar melhor a perspectiva de seus interlocutores. Carvalho e Müller (2010), por sua vez, recomendam que os pesquisadores busquem não julgar o que é dito e que não cedam à tentação de ouvir o que pretendem ouvir. Ferreira (2010) destaca a necessária abertura ao outro "na qualidade de pessoa complexa", que não se 
enquadra nas categorias sociais que pesam sobre ele. Esse é também o sentido da recomendação feita por Souza e Salgado (2008): assumir o dialogismo e a alteridade como marcas das relações no contexto de pesquisa.

Em relação à análise, Kramer (2002) e Campos (2008) sugerem que o pesquisador deixe fluir a fala das crianças ao mesmo tempo em que explicita as suas condições de produção. A preocupação de que as falas das crianças não fiquem soltas no texto, mas sirvam de fato para que exploremos o seu "contributo único à compreensão e teorização acerca do mundo social" é sublinhada por Fernandes (2016, p. 773).

Por fim, o nono grupo de recomendações refere-se à escrita e divulgação da pesquisa. Compõem este grupo recomendações sobre a importância de se criarem condições para que as crianças possam se reconhecer no texto que é escrito sobre elas (KRAMER, 2002; FERNANDES, 2016); sobre a descrição densa do lugar a partir do qual o pesquisador fala e escuta (LEITE, 2008; BARBOSA, 2014); e sobre os cuidados com os usos de imagens e de nomes de crianças (KRAMER, 2002; BARBOSA, 2014).

Em relação aos resultados obtidos, identificamos recomendações sobre a preocupação com a aplicação prática (LISBOA; HABIGZANG; KOLLER, 2008). Para Castro (2008), Ferreira (2008) e Kosminsky (2010), as pesquisas devem contribuir para incitar à reflexão crítica sobre as práticas sociais que afetam a vida das crianças. Kramer (2002) e Barbosa (2014) sugerem que as crianças participem da decisão sobre como os dados serão utilizados. De forma menos ambiciosa, mas sem dúvida relevante, alguns autores enfatizam a importância de devolver os dados para as crianças e para a comunidade envolvida (MOREIRA, 2008; CARVALHO; MÜLLER, 2010; ALVARENGA et al., 2012, entre outros).

\section{considerações finais}

Ao final desse estudo, retomamos o nosso objetivo, que foi a elaboração de um "estado da arte" de produções brasileiras acerca da ética nas pesquisas com crianças nas ciências humanas e sociais. Pesquisas com essa proposta de oferecer uma visão panorâmica sobre determinado campo de estudos são importantes 
especialmente quando focalizam áreas recentes de produção de conhecimento, campos ainda em construção - como é o caso aqui -, pois trazem possibilidades de observarmos pontos de divergência, temas silenciados ou ainda pouco abordados, apontando linhas de investigação a serem seguidas com o objetivo de adensar a produção do campo. Chamamos atenção, nesse sentido, para duas ausências que nos parecem indicar a importância de novas pesquisas com possibilidades de significativas repercussões para a consolidação dessa área. A primeira delas referese à inexistência de reflexões sobre preocupações e dilemas éticos em pesquisas com o envolvimento de bebês, um grupo geracional que desafia pesquisadores em seu intento de considerar como sujeitos e atores sociais os participantes da pesquisa; um grupo que, exceto na psicologia, historicamente esteve ausente nas investigações em CHS, mas que em anos muito recentes passa a ter, nas palavras de Alanen (2001), “autonomia conceitual”, isto é, passa a ser reconhecido como um grupo importante de ser estudado por si mesmo e não apenas como variável dependente de categorias como família ou escola.

A segunda escassez importante de ser destacada refere-se às contribuições de cientistas sociais, especialmente antropólogos, que vêm de uma longa tradição de reflexão ética nas relações entre pesquisadores e "pesquisados", estando particularmente atentos ao incessante risco do pesquisador assumir uma postura etnocêntrica em seu percurso de investigação. Autores dessa área têm sido protagonistas das críticas dirigidas ao “biocentrismo" (GUERRIEIRO; MINAYO, 2013; LANGDON; MALUF; TORNQUIST, 2016) que caracteriza a visão de pesquisa expressa em boa parte dos documentos e das instâncias que têm a atribuição formal de regular a ética na pesquisa com seres humanos. De fato, a antropologia tem se deparado com questões que vão além da dimensão metodológica e que se referem, por exemplo, a como efetivamente pensar indivíduos e grupos pesquisados como "sujeitos" da pesquisa e não somente fonte de informação; ou ao uso de etnografias para a construção de políticas e ações governamentais que acabam prejudicando esses mesmos grupos. Deste modo, a ética se afirma como "adoção de uma postura reflexiva e crítica no que diz respeito 
à própria pesquisa", que é inseparável da política uma vez que envolve questões relativas aos "desdobramentos da 'situação colonial', como a desigualdade e iniquidade nas relações pesquisadores-pesquisados, ou entre agentes de política pública, gestores e sujeitos dessa (a essa) política" (LANGDON; MALUF; TORNQUIST, 2016, p. 120). Parece-nos que seriam valiosas as contribuições de antropólogos para melhor entendermos as tensões que estão em jogo quando focalizamos as crianças ao abordar o tema da ética em pesquisa.

Reafirmamos, ao final desse estudo, a importância da articulação entre os textos que problematizam a legislação sobre ética em pesquisa com seres humanos e os estudos que se dedicam a refletir sobre a ética especificamente em pesquisa com crianças. Por um lado, como pesquisadores da área da infância temos contribuições a dar para os debates acerca da regulamentação ética das pesquisas, refletindo sobre as (in)adequações da legislação e dos trâmites burocráticos à ela relacionada, a partir do olhar para um grupo - o das crianças - que, em nome de sua proteção, vem sendo sistematicamente enquadrado como vulnerável, dificultando o reconhecimento de sua autonomia e suas competências, em contextos específicos. Por outro lado, direcionar o olhar para a legislação e para as instâncias reguladoras pode permitir que pesquisadores da infância comparem posições destinadas às crianças com a de outros grupos etários de forma a, talvez, observar modos como o adultocentrismo opera na sociedade.

Podem ser interessantes também estudos que se proponham a iluminar distinções (e aproximações) entre questões e dilemas éticos que se apresentam nas pesquisas com crianças nas ciências biomédicas e nas ciências humanas e sociais.

Concordamos com o posicionamento que nos pareceu central na bibliografia aqui analisada: a ênfase na postura permanentemente crítica do(a) pesquisador(a) que se propõe a desenvolver uma investigação com crianças deve estar na consideração das crianças como atores sociais, bem como na desconstrução da noção de incapacidade sócio-política da criança e do jovem. Além disso, este conjunto de textos defende que preceitos éticos não são suficientes para assegurar tal inflexão, sendo necessária uma nova compreensão 
da posição das crianças em pesquisas e outro posicionamento ético-político do pesquisador.

Tal é a direção assumida por Andrade e Rosemberg (2004) para enfrentar o discurso estigmatizante sobre crianças pobres. Do conjunto de princípios arrolados pelos dois pesquisadores, destacamos dois: “ter claro que a preservação da dignidade, privacidade e integridade física, psíquica, moral, religiosa e cultural da criança ou adolescente em situação de vulnerabilidade deve superar qualquer outro interesse da pesquisa"; e "ter cuidado com interpretações que reforcem o prognóstico de um destino inexorável a partir das condições atuais de vulnerabilidade em que vivem crianças e adolescentes".

Essa direção ética e política ganha maior importância quando consideramos, como Marchi e Sarmento (2017), que um elemento paradoxal dos direitos da criança é o de sua promulgação num momento em que as condições estruturais para sua efetivação já apareciam fortemente afetadas pelas profundas desigualdades geradas na sociedade contemporânea, como consequência da globalização hegemônica do modelo de capitalismo financeiro. Assim, e mais especificamente, no caso do Brasil, as desiguais condições de vida das crianças colocam compromissos de ordem política para os pesquisadores seja quanto aos parâmetros éticos, seja quanto aos temas e aos desenhos das pesquisas. Por exemplo: quais os limites do sigilo e do silêncio dos pesquisadores quando se observa em campo situações que atentam contra os direitos humanos?

Problematizar o lugar social de crianças e as discriminações a que estão expostas contribui para fazer valer, na vida acadêmica, noções como proteção, respeito e direito à participação. As pesquisas são lócus estratégico para tais questionamentos, na medida em que participam das modelizações teóricas e políticas no tocante à infância.

\section{referências}

ALANEN, L. Estudos feministas/estudos da infância: paralelos, ligações e perspectivas. In: CASTRO, L. R. (Org.). Crianças e jovens na construção da cultura. Rio de Janeiro: Nau, 2001. p. 69-92. 
ANDRADE, L. F.; ROSEMBERG, F. Princípios éticos que devem nortear a produção e divulgação de peças-texto e imagem sobre a infância e adolescência em situação de vulnerabilidade social. In: ANDRADE, L. Prostituição infanto-juvenil na mídia: estigmatização e ideologia. São Paulo: EDUC, 2004. p. 183-185.

ARIÈS, P. História social da criança e da família. Rio de Janeiro: Zahar, 1981.

BARDIN, L. Análise de conteúdo. Lisboa: Edições 70, 2002.

BOURDIEU, P. Compreender. In: Bourdieu, P. A miséria do mundo. Petrópolis: Vozes, 1999. p. 693-713.

CASTRO, L. R. Conhecer, transformar(-se) e aprender: pesquisando com crianças e jovens. In: CASTRO, L. R.; BESSET, V. (Org.). Pesquisa-intervenção na infância e juventude. Rio de Janeiro: Trarepa/FAPERJ, 2008. p. 21-42.

FONSECA, C. O anonimato e o texto antropológico: dilemas éticos e políticos da etnografia 'em casa'. Teoria e Cultura, v. 2, n.1, p. 39-53, 2008.

LA TAILLE, Y.; SOUZA, L. S.; VIZIOLI, L. Ética e educação: uma revisão da literatura educacional de 1990 a 2003. Educ. Pesqui. v. 30, n.1, p. 91-108, 2004.

LANGDON, E. J. ; MALUF, S. W. ; TORNQUIST, C. S. Ética e política em pesquisa: os métodos qualitativos e seus resultados. In: Esther Jean Langdon; Márcia Grisotti. (Org.). Políticas públicas: reflexões antropológicas. 1. ed.Florianópolis: Ed. UFSC, 2016, v. 1 , p. 105-123.

LOURAU, R. A análise institucional. Petrópolis: Vozes, 1996.

MARCHI, R. C.; SARMENTO, M. J. Infância, normatividade e direitos das crianças: transições contemporâneas. Educ. Soc. v. 38, n. 141, p. 951-964, out./dez. 2017. Disponível em: <http:/ /dx.doi.org/10.1590/es0101-73302017175137>

MELO, E. R. Nietzsche e a Justiça. Perspectiva: São Paulo, 2010.

GUERRIERO, I. C. Z.; MINAYO, M. C. S. O desafio de revisar aspectos éticos das pesquisas em ciências sociais e humanas: a necessidade de diretrizes específicas. Physis, Rio de Janeiro, v. 23, n. 3, p. 763-782, set. 2013.

PRADO, R. L. C.; FREITAS, M. C. Mulheres na escuta de crianças: considerações acerca do perfil de quem pesquisa com crianças nas ciências humanas e sociais brasileiras (no prelo).

ROSEMBERG, F.; MARIANO, C. S. A Convenção Internacional sobre os Direitos da Criança: debates e tensões. Cad. Pesqui. v. 40, n. 141, p. 693-728, 2010.

SOARES, N. F. A investigação participativa no grupo da infância. Currículo sem Fronteiras, v. 6, n.1, p. 25-40, 2006.

\section{Apêndice I - Bibliografia analisada}

ALDERSON, P. As crianças como pesquisadores: os efeitos dos direitos de participação sobre a metodologia de pesquisa. Educ. Soc. v. 26, n. 91, p. 419-442, 2005.

ALVARENGA, P. et al. Questões éticas da pesquisa em Psicologia do Desenvolvimento. Psicol. cienc. prof. v. 32, n. 4, p. 856-871, 2012.

BARBOSA, M. C. S. A ética na pesquisa etnográfica com crianças: primeiras problematizações. Práxis Educativa, v. 9, n. 1, p. 235-245, jan./jun. 2014.

CAMPOS, M. M. Por que é importante ouvir a criança? A participação das crianças pequenas na pesquisa científica. In: CRUZ, S. H. (Org.). A criança fala: a escuta de crianças em pesquisas. São Paulo: Cortez, 2008. p. 35-42.

CARVALHO, A.; MÜLLER, F. Ética nas pesquisas com crianças: uma problematização necessária. In: MÜLLER, F. (Org.). Infância em perspectiva: políticas, pesquisas e instituições. São Paulo: Editora Cortez, 2010. p. 65-84. 
CASTRO, L. R. Conhecer, transformar(-se) e aprender: pesquisando com crianças e jovens. In: CASTRO, L. R.; BESSET, V. L. (Org.). Pesquisa-intervenção na infância e juventude. Rio de Janeiro: Trarepa/FAPERJ, 2008. p. 21-42.

CORREA, J. A pesquisa-intervenção na investigação do aprendizado da escrita. In: CASTRO, L. R.; BESSET, V. L. (Org.). Pesquisa-intervenção na infância e juventude. Rio de Janeiro: Trarepa/FAPERJ, 2008. p. 274-293.

CRUZ, S. H. V. Ouvir crianças: uma tarefa complexa e necessária. In: SOUZA, M. P. R. (Org.). Ouvindo crianças na escola: abordagens qualitativas e desafios metodológicos para a psicologia. São Paulo: Casa do Psicólogo, 2010. p. 11-19.

DELGADO, A. C. C.; MULLER, F. Abordagens etnográficas nas pesquisas com crianças e suas culturas. In: CRUZ, S. H. (Org.). A criança fala: a escuta de crianças em pesquisas. São Paulo: Cortez, 2008. p. 141-157.

DELGADO, A. C. C.; MULLER, F. Apresentação. Educ. Soc., v. 26, n. 91, p. 351-360, 2005 a.

DELGADO, A. C. C.; MULLER, F. Em busca de metodologias investigativas com as crianças e suas culturas. Cad. Pesqui., v. 35, n.125, p. 161-179, 2005 b.

DIAS, A. C.; LEME, M. I.; KOLLER, S. H. Ética na pesquisa com crianças. Imaginário (USP), v. 17/18, p. 493-506, 2009.

FERNANDES, N. Ética na pesquisa com crianças: ausências e desafios. Rev. Bras. Educ., Rio de Janeiro, v. 21, n. 66, p. 759-779, set. 2016.

FERREIRA, M. "Branco demasiado" ou reflexões epistemológicas, metodológicas e éticas acerca da pesquisa com crianças. In: SARMENTO, M.; GOUVEA, M. C. (Orgs.). Estudos da Infância: Educação e Práticas Sociais. Petrópolis: Vozes, 2008. p. 143-162.

FERREIRA, M. “-Ela é nossa prisioneira!” Questões teóricas, epistemológicas e éticometodológicas a propósito dos processos de obtenção da permissão das crianças pequenas numa pesquisa etnográfica. Reflexão e Ação, v. 18, p. 151-182, 2010.

FRANCISCHINI, R.; FERNANDES, N. Os desafios da pesquisa ética com crianças. Estud. psicol. (Campinas), v. 33, n. 1, p. 61-69, mar. 2016.

FREITAS, M. C.; PRADO, R. L. C. A pesquisa envolvendo seres humanos à luz dos estudos sociais da infância. In: FREITAS, M. C.; PRADO, R. L. C. O professor e as vulnerabilidades infantis. São Paulo: Cortez, 2016. p.93-119.

FUNDAÇÃO CARLOS CHAGAS (FCC). Implicações éticas provenientes da utilização de crianças como sujeito de pesquisa. Cad. Pesqui., v. 31, p. 17-33, 1979.

KOSMINSKY, E. Pesquisas com crianças e jovens: algumas reflexões teóricometodológicas. In: MÜLLER, F. (Org.). Infância em perspectiva: políticas, pesquisas e instituições. São Paulo: Editora Cortez, 2010. p.110-139.

KRAMER, S. Autoria e autorização: questões éticas nas pesquisas com crianças. Cad. Pesqui., v. 116, p. 41-59, 2002.

LEITE, M. I. Espaços de narrativa - onde o eu e o outro marcam encontro. In: CRUZ, S. H. V. (Org.). A criança fala: a escuta de crianças em pesquisas. São Paulo: Cortez, 2008. p. 118140.

LISBOA, C.; HABIGZANG, L.; KOLLER, S. H. Ética na pesquisa com temas delicados: estudos em psicologia com crianças e adolescentes vítimas de violência doméstica. In: GUERRIERO, I. Z.; SCHMIDT M. L. S.; ZICKER, F. (Org.). Ética nas pesquisas em Ciências Humanas e Sociais na Saúde. São Paulo: HUCITEC, 2010. p. 176-192.

MOREIRA, M. I. C. Pesquisa-intervenção: suas especificidades e aspectos da integração entre pesquisadores e sujeitos de pesquisa. In: CASTRO, L. R.; BESSET, V. L. (Org.). Pesquisa-intervenção na infância e juventude. Rio de Janeiro: Trarepa/FAPERJ, 2008. p. 409432. 
PEREIRA, R. M. R. Precisamos conversar! Questões para pensar a pesquisa com crianças na cibercultura. In: REIS, M.; GOMES, L. O. (Org.). Infância: sociologia e sociedade. São Paulo: Levana, 2015. p. 259-280.

SANT'ANA, R. B. Criança-sujeito: experiências de pesquisas com alunos de escolas públicas. In: SOUZA, M. P. R. (Org.). Ouvindo crianças na escola: abordagens qualitativas e desafios metodológicos para a psicologia. São Paulo: Casa do Psicólogo, 2010. p. 30-53.

SOLON, L. A. G.; COSTA, N. R. A.; ROSSETTI-FERREIRA, M. C. Conversando com crianças. In: CRUZ, S. H. V. (Org.). A criança fala: a escuta de crianças em pesquisas. São Paulo: Cortez, 2008. p. 204-224.

SOUZA, S. J.; SALGADO, R. G. Mikhail Bakhtin e a ética das imagens nos estudos da infância: uma proposta de pesquisa-intervenção. In: CASTRO, L. R.; BESSET, V. L. (Org.). Pesquisa-intervenção na infância e juventude. Rio de Janeiro: Trarepa/FAPERJ, 2008. p. 490513.

SPINELLI, C. S.; QUINTEIRO, J. A criança na pesquisa educacional brasileira: da condição de "silenciada" à "testemunha da história". In: REIS, M.; GOMES, L. O. (Org.). Infância: sociologia e sociedade. São Paulo: Levana, 2015. p. 349-371.

TOMÁS, C. A. A investigação sociológica com crianças: caminhos, fronteiras e travessias. In: CASTRO, L. R.; BESSET, V. L. (Org.). Pesquisa-intervenção na infância e juventude. Rio de Janeiro: Trarepa/FAPERJ, 2008. p. 387-408.

recebido em: 26.09 .2017

aceito em: 23.10 .2017 